Int. J. Electrochem. Sci., 13 (2018) $8905-8914$

\title{
High Sensitive Sandwich-type Electrochemical IgG Immunosensor Based on a Nanocomposite of Carbon Nanotube and Multifunctional Ionic Liquid Containing Aldehyde and Ferrocene Groups as Labels
}

\author{
Youming Shen ${ }^{1}$, Guangyu Shen ${ }^{1}$, Youyu Zhang ${ }^{2, *}$ \\ ${ }^{1}$ Hunan Province Cooperative Innovation Center for The Construction \& Development of Dongting \\ Lake Ecological Economic Zone, College of Chemistry and Material Engineering, Hunan University \\ of Arts and Science, Changde, 415000, PR China \\ ${ }^{2}$ Key Laboratory of Chemical Biology and Traditional Chinese Medicine Research (Ministry of \\ Education), College of Chemistry and Chemical Engineering, Hunan Normal University, Changsha \\ 410081, PR China \\ *E-mail: sgyrab@163.com, zhangyy@hunnu.edu.cn
}

doi: $10.20964 / 2018.09 .29$

Received: 21 May 2018 / Accepted: 14 June 2018 / Published: 5 August 2018

Using a nanocomposite of carbon nanotube and multifunctional ionic liquid as labels and chitosan as platform, we fabricated a sandwich-type electrochemical immunosensor. The multifunctional ionic liquid was anchored with both aldehyde groups and ferrocene groups. Aldehyde groups were used to bond the second antibody and ferrocene groups were used as signal probes. Due to the large surface area of carbon nanotube, increased-loading of ferrocene was obtained, which improved the sensitivity of the immunosensor. In addition, the high conductivity of carbon nanotube and ionic liquid also enhanced the sensitivity of the immunosensor. The fabricated immunosensor showed a good performance. The linear range was from 0.05 to $30 \mathrm{ng} \mathrm{mL}^{-1}$ with a detection limit of $0.01 \mathrm{ng} \mathrm{ml}^{-1}$ $(S / N=3)$, which is 40 times higher than that of reported immunsensor for human IgG based on ferrocene as labels. We anticipate this strategy may provide a new platform for the clinic application.

Keywords: Multifunctional ionic liquid; Ferrocene; Carbon nanotube; Sandwich-type electrochemical immunosensor; Human IgG.

\section{$\underline{\text { FULL TEXT }}$}

(C) 2018 The Authors. Published by ESG (www.electrochemsci.org). This article is an open access article distributed under the terms and conditions of the Creative Commons Attribution license (http://creativecommons.org/licenses/by/4.0/). 